\title{
The Effects of Business Model Innovation of Internet Finance Enterprises on Competitive Advantages
}

\author{
Yuyang $\mathrm{LI}^{1}$, Wei $\mathrm{LI}^{2}$ \\ ${ }^{1}$ Department of Quality Development Chongqing Youth Vocational \& Technical College Chongqing, China \\ ${ }^{2}$ School of Management Chongqing University of Technology, CQUT Chongqing, China
}

\begin{abstract}
The business model innovation (BMI) of internet finance enterprises (IFEs), as a revolutionary reconstruction of traditional financial services, would inevitably have significant impact on the formation of the competitive advantage of IFEs. Based on the distinction between exploratory and exploitative BMI, this paper discusses the realization path of the effects of BMI in IFEs on competitive advantage from the perspective of customer equity. We find that customer equity as a key intermediary variables, play a critical role on the relationship between BMI and competitive advantage of IFEs.
\end{abstract}

\section{INTRODUCTION}

With the influence of Internet technology and thought of value creation, the traditional financial service continues to innovate business models, and the iterations of science and technology have forced traditional financial firms to create new competitive advantages [1]. Most studies explored innovational behavior in SMEs and manufacturing enterprises, while there is still a lack of research on business model innovation (BMI) in service enterprises [2]. In fact, BMI has been regarded as a repeatable source of competitive advantages, but the research on the implementation mechanism is still in its infancy [3].

Customer equity has been regarded as the most important resource for firms to gain competitive advantages and sustainable growth [4], and then BadenFuller and Haefliger [5] proposed that enterprises, in face of diverse customers and changing technology, should adopt new business models by concentrating on consumers, analyzing their preferences and exploiting their potential needs. Therefore, we attempt to distinguish the two types of BMI, and explore the mechanism of how BMI of internet finance enterprises (IFEs) drives competitive advantages under the perspective of customer equity.

\section{Business model innovation of IFEs}

BMI refer to a means to implement innovation strategy serving as a kind of innovation activity following technological and managerial innovation. In the internet era, driven by the unprecedented development of digital technology, IFEs tend to reform their organizational structure and business model. The open innovation theory emphasizes that building a business model requires the match of core technologies with the market [1]. Therefore, it is necessary to transform traditional businesses and create opportunities and new markets by creatively exploiting the emerging and disruptive technology.

In fact, the BMI of IFEs is the revolutionary reconstruction of the traditional service industry by using ICT (Information Communications Technology) under the conditions of uncertainty, high risk and great complexity. So, we follow the divide BMI into two types: exploratory BMI and exploitative BMI: exploratory BMI pertains to IFEs provide financial services different from traditional market and create new value for target customers, while exploitative BMI pertains to IFEs optimize and improve traditional financial services, or satisfy customers by the renewed financial services [6]. In short, the exploratory $\mathrm{BMI}$ is disruptive and innovative, while exploitative BMI is successive and continuous.

\section{Business model innovation and customer equity}

Customer equity is considered to be the total discounted amount of the customer's lifetime value, reflecting that the focus of market competition shifts from products to customers. In order to better understand customer equity, existing studies have attempted to identify key components or drivers of customer equity. Customer acquisition, retention, and development are core factors of customer equity [7].

However, the three-dimensional model, namely value equity, brand equity and relationship equity is the best path for building customer equity, and has been discussed [8]. Furthermore, value equity is the subjective judgement of the costs and benefits of services provided, which may be affected by the price, quality and convenience of the product or service; relationship equity reflects customers' tendency of customers to establish long-lasting 
relationships with enterprises, and the reliance and trust on companies and services after experiencing those services; brand equity indicates the subjective evaluation of product brands, which surpasses the value of the product or service itself, which may be influenced by customers' impressions on the brand image and even the firm. Value equity, relationship equity and brand equity are strategic investment portfolios that ultimately affect customer equity. Therefore, we regard customer equity as a mediating role on relationship between BMI and competitive advantages.

Exploratory BMI emphasizes that IFEs usually provide different financial services, employ new technological resources to create and deliver new service value to target customers [6]. First, the design and development of new services mostly satisfy the potential needs of customers, thereby enhancing customer value propositions. Secondly, meeting the demands of customers is an approach to enhance their trust and attachment on the IFEs, thereby enhancing customer stickiness. Finally, exploratory activities in financial service design will ultimately satisfy needs and exert positive effects on brand equity.

In short, exploratory BMI effectively improves the level of customer value, strengthens customer relationships, and optimizes customers' propositions of services, by developing new services, creating new customer values, and satisfying potential customers. Therefore, we propose:

P1: Exploratory BMI has a positive impact on customer equity.

The exploitative BMI emphasizes that IFEs tend to optimize existing financial services, or introduce existing financial services into new markets, which emphasize the integration and utilization of existing resources to seize the white space, increase the added values, and achieve the fullness of demands. On the one hand, the IFEs adopting exploitative business model incline to integrate new resources and capabilities by making the best of the resources at hand and enhance services value proposition. On the other, the IFEs conduct implement exploitative activities by investing more resources to fully tap customer needs, in order to match the needs of financial services, enhance the relationship between companies and customers, and improve relationship equity ultimately [9].

In summary, exploitative BMI enhances the customer's value by integrating existing resources, enhancing the competitiveness continuously, improving the perception of customer and enhancing the trust and attachment on the company, which ultimately perfects the IFEs image as well as service brand. So, we propose:

P2: Exploitative BMI has a positive impact on customer equity.

\section{Customer equity and competitive advantages}

With unprecedented environmental dynamisms and policy regulations, the IFEs should fix their eyes on fostering unique competitive advantages in order to gain a dominant position in the competition. The resource-based view holds that competitive advantages are intended to use resources to meet the demands more effectively than competitors. From the perspective of competitive strategy, competitive advantages can be decomposed into two dimensions: relatively low cost and excess customer value [10]. Therefore, we distinguish the competitive advantages of IFEs in terms of cost and differentiation: low-cost advantages signify that IFEs have lower cost levels than the average of the financial industry; differentiation advantages reflect unique characteristics in terms of the service brand, service technology, and service response speed and effectiveness to customers and competitors.

Though the discussion on relationship between customer equity and competitive advantages is still lack, previous studies have reached a consensus that customers are more important organizational assets than equipment, capital, talents and technology [11]. In fact, the IFEs should effectively manage customers and strive to accumulate customer equity, which will ultimately increase corporate values and boost competitive advantages. Whether it is low-cost advantage or differentiation competitive advantage or, customers are the leading source of competitive advantages.

In terms of constructing low-cost advantages, the IFEs acquiring high-level customer equity tend to implement cost-oriented strategies. This is mainly because of the following reasons: Firstly, the creation and accumulation of customer value could create low-cost advantages. Once the IFEs explore competitive value propositions and focus on creating and delivering customer value, they have the chance to form economies of scale based on specific customer value creation activities, thus becoming low-cost competitors [12]. Secondly, customer relationship are influential to acquire cost advantages. Value-creation, based on high-quality customer relationships, brings costeffectiveness to activities such as service development and improvement, word-of-mouth communication, so that the overall operating cost of the IFEs is lower than the average one [13]. Finally, the positive brand image of the IFEs or service could strengthen the level of customers' reliance and attachment on certain products or services, which may increase the switching costs and ultimately achieving customer lock-in; while the cluster of stable customers enables the company to lower the investment in product development, and invest more resources to cut down the costs. So, we propose:

P3: Consumer equity has a positive impact on low-cost advantages.

Even though the discussions on the relationship between customer equity and differentiation competitive advantages are still insufficient, some studies have explored factors that may trigger competitive advantages, and the role of factors such as customer value, customer relationship and brand equity have been empirically tested [14]. On the one hand, in terms of customer value creation and delivery, focusing on customer value helps IFEs to deeply understand customer needs, and engage in accumulating key resources, such as technology patents and service channels, to form differentiated and inimitable competitive advantages. On the other hand, a close and interactive customer relationship, that is, a high-level 
relationship asset, enhances the extent of connection between the IFEs and its customers, strengthens the degree of embedding and transaction exclusivity, and triggers new unreplaceable needs, which enables companies to have differentiated characteristics in the market competition [15]. In addition to technical assets, the brand image is another driver of corporate differentiation. Building a specific brand image can not only strengthen customers' impressions on it, but also help the IFEs to obtain the brand premium ability and win differentiated brand advantages in the homogenization competition [16].

Therefore, the creation and transmission of customer value, the construction and maintenance of customer relationships, and the formation of unique brand images and brand equity facilitates the IFEs to provide competitive services, enabling them to win differentiated competitive advantages as a result. Hence, we propose:

P4: Consumer equity has a positive impact on differentiation advantages.

Based on the above propositions, an effect mechanism of BMI in IFEs is formed as following (fig.1)

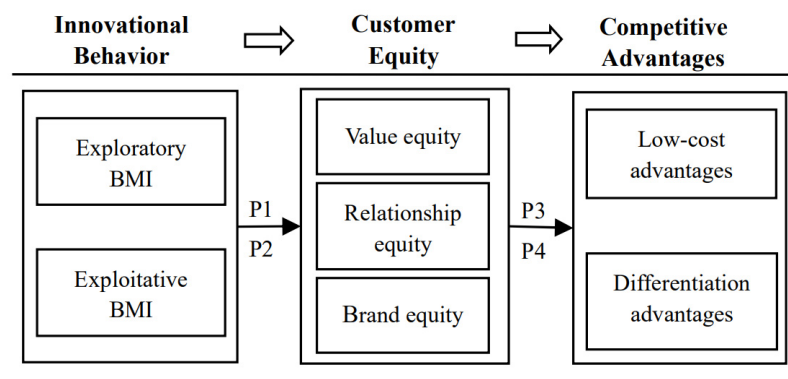

Fig 1. Effects mechanism of BMI

\section{Conclusion}

In this paper, we regard customer equity as an intermediary variable, and explore the mechanism of BMI affecting competitive advantages in the IFEs. On the one hand, customer equity is composed of several key elements of value, relationship and brand, and different elements are affected by exploratory and exploitative BMI of the IFEs. On the other hand, the IFEs have different goals for building competitive advantages, and should pay attention to the key dimensions of customer equity at a different level. That means, focusing on customer value should be the most critical part of service enterprises to implement BMI of the IFEs and build competitive advantages.

The theoretical contributions are listed as follows: Firstly, it enriches the literatures on BMI in terms of its classification and utility mechanism. From the perspective of disruptive innovation, we divide the BMI into two types, exploratory BMI and exploitative BMI, which expands the theoretical understanding of BMI. Secondly, we take customer equity as value equity, relationship equity and brand equity, and we also link customer equity with business performance at the strategic level to explore the mechanism of BMI driving competitive advantages. Thirdly, we expand the research on the antecedents and outcomes of customer equity, and consider BMI as an important antecedent of customer equity, which enriches the research on key elements affecting customer equity.

Our study on the impact mechanism of BMI in the IFEs on the competitive advantages mainly focused on the intermediary effects of customer equity; there are other important variables, such as customer satisfaction, consumer reservation, and word of mouth, which could also play important roles in the utility mechanisms of BMI need to be explored in future research. Additionally, in terms of the object of study, we focus on the IFEs, but Internet finance is an emerging business form, and the overall number of enterprises is relatively small and the quality is uneven, which exerts negative impacts on the research insights. In the meantime, we only analyze the relationship between business model innovation and competitive advantage from the theoretical level, and still lacks in-depth analysis of some specific phenomena. So, future studies should use large sample data or typical cases to verify and expand the theoretical viewpoints so as to strengthen our understanding for BMI of Internet finance.

\section{ACKNOWLEDGMENT}

We gratefully appreciate the funding provided by the National Natural Science Foundation of China under Grant No. 71872024; Humanities and Social Sciences Fund of Ministry of Education of China under Grant No. 17YJC630066.

\section{References}

1. H. Chesbrough, "Business model innovation: opportunities and barriers. Long Range Planning", vol. 43, pp. 354-363, March 2010.

2. M. Anwar, "Business model innovation and SMEs performance: Does competitive advantage mediate? International Journal of Innovation Management", vol. 22, pp. 185-197, July 2018.

3. R. Casadesus-Masanell, \& J. Ricart, "How to design a winning business model", Harvard Business Review, vol. 89, pp. 100-107, Feb 2011.

4. H. Zhang, E. Ko, \& E. Lee, "Moderating Effects of Nationality and Product Category on the Relationship between Innovation and Customer Equity in Korea and China. Journal of Product Innovation Management", vol. 30, pp. 110-122, Jan 2013.

5. C. Baden-Fuller. \& S. Haefliger, "Business models and technological innovation. Long Range Planning", vol. 46, pp. 419-426, June 2016.

6. A. Kim. \& E. Ko, "Do social media marketing activities enhance customer equity? An empirical study of luxury fashion brand. Journal of Business Research", vol. 65, pp. 1480-1486, Oct 2012.

7. I. Kastalli. \& Van Looy, B, "Servitization: Disentangling the impact of service business model innovation on manufacturing firm performance", Journal of Operations Management, vol. 31, pp. 169180, April 2013.

8. P. Sok. \& A. O'Cass, "Achieving service quality through service innovation exploration-exploitation: 
the critical role of employee empowerment and slack resources", Journal of Services Marketing, vol. 29, pp. 137-149, Feb 2015.

9. C. Wang. \& P. Ahmed, "Dynamic capabilities: A review and research agenda", International Journal of Management Reviews, vol. 9, pp 31-51, Jan 2007.

10. O. Iglesias, S. Markovic, \& J. Rialp, "How does sensory brand experience influence brand equity? Considering the roles of customer satisfaction, customer affective commitment, and employee empathy", Journal of Business Research, vol. 96, pp. 343-354, Nov 2015.

11. B. Berman, "How to compete effectively against lowcost competitors", Business Horizons, vol. 58, pp. 8797, Jan 2015.

12. N. Tzokas, Y. Kim, H. Akbar, \& H. Al-Dajani, "Absorptive capacity and performance: The role of customer relationship and technological capabilities in high-tech SMEs", Industrial Marketing Management, vol. 47, pp. 134-142, Dec 2015.

13. A. Amini, M. Darani, M. Afshani, \& Z. Amini, "Effectiveness of marketing strategies and corporate image on brand equity as a sustainable competitive advantage", Interdisciplinary Journal of Contemporary Research in Business, vol. 4, pp. 192205, Feb 2015.

14. D. Mahr, A. Lievens, \& V. Blazevic, "The value of customer cocreated knowledge during the innovation process", Journal of Product Innovation Management" vol. 31, pp. 599-615, March 2014.

15. K. Chatzipanagiotou, C. Veloutsou, \& G. "Christodoulides, Decoding the complexity of the consumer-based brand equity process", Journal of Business Research, vol. 69, pp. 5479-5486, Nov 2016.

16. M. Renton, U. Daellenbach, S. Davenport, \& J. Richard, "Small but sophisticated: Entrepreneurial marketing and SME approaches to brand management", Journal of Research in Marketing and Entrepreneurship, vol. 17, pp. 149-164, Jan 2015. 